\title{
Durable Expression of Minicircle DNA-Liposome-Delivered Androgen Receptor cDNA in Mice with Hepatocellular Carcinoma
}

\author{
Tian-You Chang, ${ }^{1,2}$ Chin-Ying Chung, ${ }^{3}$ Wei-Min Chuang, ${ }^{1,2}$ Long-Yuan Li, ${ }^{1}$ \\ Long-Bin Jeng, ${ }^{1}$ and Wen-Lung $\mathrm{Ma}^{1,2}$ \\ ${ }^{1}$ Sex Hormone Research Center, Center for Molecular Medicine, and Organ Transplantation Center, China Medical University Hospital, \\ Taichung 404, Taiwan \\ ${ }^{2}$ Graduate Institution of Clinical Medical Science, Department of Medicine, School of Medicine, China Medical University, \\ Taichung 404, Taiwan \\ ${ }^{3}$ Department of Pharmacology, The Pennsylvania State University College of Medicine, Hershey, PA 17033, USA
}

Correspondence should be addressed to Wen-Lung Ma; maverick@mail.cmu.edu.tw

Received 4 September 2013; Revised 25 December 2013; Accepted 21 January 2014; Published 6 March 2014

Academic Editor: Guillermo Mazzolini

Copyright (C) 2014 Tian-You Chang et al. This is an open access article distributed under the Creative Commons Attribution License, which permits unrestricted use, distribution, and reproduction in any medium, provided the original work is properly cited.

Background. The most common gene-based cancer therapies involve the suppression of oncogenic molecules and enhancement of the expression of tumor-suppressor genes. Studies in noncancer disease animal models have shown that minicircle (MC) DNA vectors are easy to deliver and that the proteins from said MC-carrying DNA vectors are expressed over a long period of time. However, delivery of therapeutic genes via a liposome-mediated, MC DNA complex has never been tested in vascularrich hepatocellular carcinoma (HCC). Liposome-mediated DNA delivery exhibits high in vivo transfection efficiency and minimal systemic immune response, thereby allowing for repetitive interventions. In this study, we evaluated the efficacy of delivering an MC-liposome vector containing a $3.2 \mathrm{~kb}$ androgen receptor (AR; HCC metastasis suppressor) cDNA into Hepatitis B Virus- (HBV-) induced HCC mouse livers. Results. Protein expression and promoter luciferase assays revealed that liposome-encapsulated MCAR resulted in abundant functional expression of AR protein $(100 \mathrm{kD})$ for up to two weeks. The AR cDNA was also successfully delivered into normal livers and diseased livers, where it was persistently expressed. In both normal livers and livers with tumors, the expression of AR was detectable for up to 60 days. Conclusion. Our results show that an MC/liposome delivery system might improve the efficacy of gene therapy in patients with HCC.

\section{Introduction}

Most solid tumors possess characteristics that are not observed in normal tissues, such as extensive angiogenesis and hence hyper-vasculature, defective vascular architecture, impaired lymphatic drainage/recovery systems, and greatly increased production of a number of permeability mediators [1]. The enhanced permeability and retention (EPR) effect is a phenomenon unique to and ubiquitous in tumors which allows macromolecules such as lipids to enter the tumor interstitial space (enhanced permeability) where they are sequestered due to suppressed lymphatic filtration (retention). The EPR effect provides a great opportunity for more selective targeting of lipid- or polymer-conjugated anticancer drugs, such as SMANCS [2], PK-1 [3], and liposomeencapsulated DNA to the tumor.

The rapid injection of a large volume of DNA solution into a vein was shown by Liu et al. to be an effective method for transfecting DNA into liver, lung, kidney, and heart [4]. The procedure, known as the hydrodynamic method, involves the application of controlled hydrodynamic pressure in capillaries to enhance endothelial and parenchymal cell permeability as a driving force for in vivo gene transfer. Gao et al. reported that the injection of a large volume of DNA solution (8 12\% of body weight) within a short time (3 $5 \mathrm{~s})$ can generate a transfection efficiency of up to $40 \%$ in 
hepatocytes [5]. This method has been used for delivery of DNA that code for small proteins, such as hemophilia factors $[6,7]$, cytokines [8], hepatic growth factors [9], and alphal antitrypsin [10] in mice and rats. Ortaldo et al. showed that hydrodynamic administration of the IL-2 gene resulted in the rapid and transient production of up to $160 \mathrm{ng} / \mathrm{mL}$ of IL-2 protein in serum [11]. However, the problem with the hydrodynamic method for gene transfer in humans is that it is not possible to achieve a good transfection efficiency using a DNA solution of up to $12 \%$ of body weight within a short period of time [12].

The duration of protein expression from genes delivered via plasmid DNA delivery is normally transient, lasting for only a few days, followed by a period of prolonged yet low level expression. It is thought that unmethylated $\mathrm{CpG}$ sequences in the plasmid backbone stimulate intracellular innate immune responses $[13,14]$. Plasmids without $\mathrm{CpG}$ sequences (i.e., minicircles (MC)) that no longer contain antibiotic resistance markers or the bacterial origin of replication but contain only the functional part of the plasmid have been shown to prolong the duration of protein expression [15]. These small vectors provide for long-term transient expression of multiple transgenes without the risks of immunogenic responses as in standard plasmids. Chen et al. [15] showed that minicircles expressed 45- and 560fold more serum human factor IX (FIX) and human alphalantitrypsin (AAT) than their parent unrecombined plasmids in mouse livers 3 weeks after transgene delivery. Yew et al. [16] showed that transfection of plasmid DNA depleted of nearly $80 \%$ of $\mathrm{CpG}$ motifs not only resulted in considerably fewer changes in blood parameters, lower levels of inflammatory cytokines, and less liver damage, but also resulted in longer transgene expression in lung and liver of immunocompetent mice than in mice that had been transfected with unmodified vector.

Hundreds of new cationic lipids have been developed since Felgner et al. first reported that a double-chain monovalent quaternary ammonium lipid, N-[17]-N,N,N- trimethylammonium chloride (DOTAP), effectively binds and delivers DNA to cultured cells [18]. The nonimmunogenic nature and ease of industrial production of these cationic lipids make them appealing for gene transfer. Currently, around $13 \%$ of gene therapy trials in progress worldwide employ nonviral liposomal vectors for transgene delivery [19]. The LPD (Liposome-Polycation-DNA) developed by Dr. Gao and Huang has shown a promising nucleic acid carrier for in vivo transfection [20]. LPD was originally designed to evade the clearance by macrophage in the reticuloendothelial system (RES) and efficiently deliver the cargo nucleic acid to the tumor cells [21-23]. The LPD was reported to cause very little immunotoxicity and negligible cytokine induction in animal tested $[21,22]$. Therefore, LPD has the potential to overcome the transfection limitations of hydrodynamic method. We applied the LPD formula for nucleic acid transfection with minor modification in this present study.

Our team has found that androgen receptor (AR), a $100 \mathrm{kD}$ nuclear transcription factor encoded by the $\mathrm{AR}$ gene measuring approximately $3.2 \mathrm{~kb}$ [24], promotes HCC initiation [25, 26] and suppresses HCC metastasis [27], indicating that AR plays dual roles in HCC progression. In a previous study, we also provided evidence that combining Sorafenib targeted therapy with ectopic AR expression leads to inhibition of HCC metastasis compared to little AR expression [27]. In this study, we used a human-relevant HBV-HCC mouse model developed by Zheng et al. [28] to examine the efficacy of delivering an MC-liposome vector containing a $3.2 \mathrm{~kb}$ androgen receptor (AR; HCC metastasis suppressor) cDNA into Hepatitis B Virus- (HBV-) induced HCC mouse livers and tested whether an MC-carrying AR DNA vector results in expression latency in tumors.

\section{Methods}

2.1. Construction of AR cDNA into Minicircle Backbone and Mass Production of Minicircle DNA. Parental plasmid with an expression cassette comprising CMV-MCS-EF1 $\alpha$-GFP (SBI) and the kanamycin resistance gene was obtained (System Bioscience, USA). The AR cDNA sequence was released from pBabe.hAR [26] using the restriction enzyme BamH1 and ligated to the parental plasmid using a T4 ligation (NEBL, USA) kit. The resulting plasmid was termed pMCP.hAR and is illustrated in Figure 1(a). In order to produce MC.hAR and MC.GFP DNA, we followed the protocol developed by Kay et al., with slight modifications [29]. In brief, pMCP.hAR and pMCP.GFP were transformed into ZYCY10P3S2T $E$. coli and the cultures were then incubated at $37^{\circ} \mathrm{C}$ in $5 \mathrm{~mL}$ LB (Luria Broth (Lennox); BIO BASIC, CA) containing $50 \mu \mathrm{g} / \mathrm{mL}$ kanamycin for $2 \mathrm{hrs}$. We then transferred the $E$. coli to a 2-liter flask containing $400 \mathrm{~mL}$ fresh TB (Terrific Broth; BIO BASIC, CA) and $50 \mu \mathrm{g} / \mathrm{mL}$ kanamycin and then incubated the culture with shaking $(250 \mathrm{rpm})$ at $37^{\circ} \mathrm{C}$ for $16 \sim 18$ hrs. We then added an equal volume of $\mathrm{LB}$ containing 2\% L-arabinose (Sigma-Aldrich), adjusted the $\mathrm{pH}$ to 7 , and further incubated the solution at $30^{\circ} \mathrm{C}$ for 5 hours with shaking. A cesium chloride $(\mathrm{CsCl})$ gradient method was used to precipitate the minicircle DNA.

2.2. Preparation of LPD Containing Minicircle DNA. $200 \mu \mathrm{L}$ of LPD for one mouse injection was prepared as previously described [21-23]. Briefly, $24 \mu \mathrm{g}$ minicircle DNA was condensed by $18 \mu \mathrm{g}$ protamine through electrostatic interaction into nanometric complexes. The complexes were mixed with $30 \mu \mathrm{L}$ of $100 \mathrm{~nm}$ cationic liposome ( $20 \mathrm{mM})$ composed of 1,2dioleoyl-3-trimethylammonium-propane (DOTAP, Avanti Polar Lipids) and cholesterol (Sigma-Aldrich) at 1:1 mol ratio. The LPD nanoparticles were then $P E G y l a t e d$ by postinsertion of $30 \mu \mathrm{L}$ of DSPE-PEG $(10 \mathrm{mg} / \mathrm{mL})$ at $50^{\circ} \mathrm{C}$ for 10 minutes.

\subsection{Injection of LPD-Containing DNA Complex into HBVtg} Mice. A single injection of subminimal dose of hepatic carcinogen diethylnitrosamine (DEN; $2 \mathrm{mg} / \mathrm{kg}$ body weight) was given to 12 - to 15 -day-old $\mathrm{HBV}$-transgenic mice as previously described [28]. The animals were provided by Professor Ou at the University of Southern California [30, 31]. 


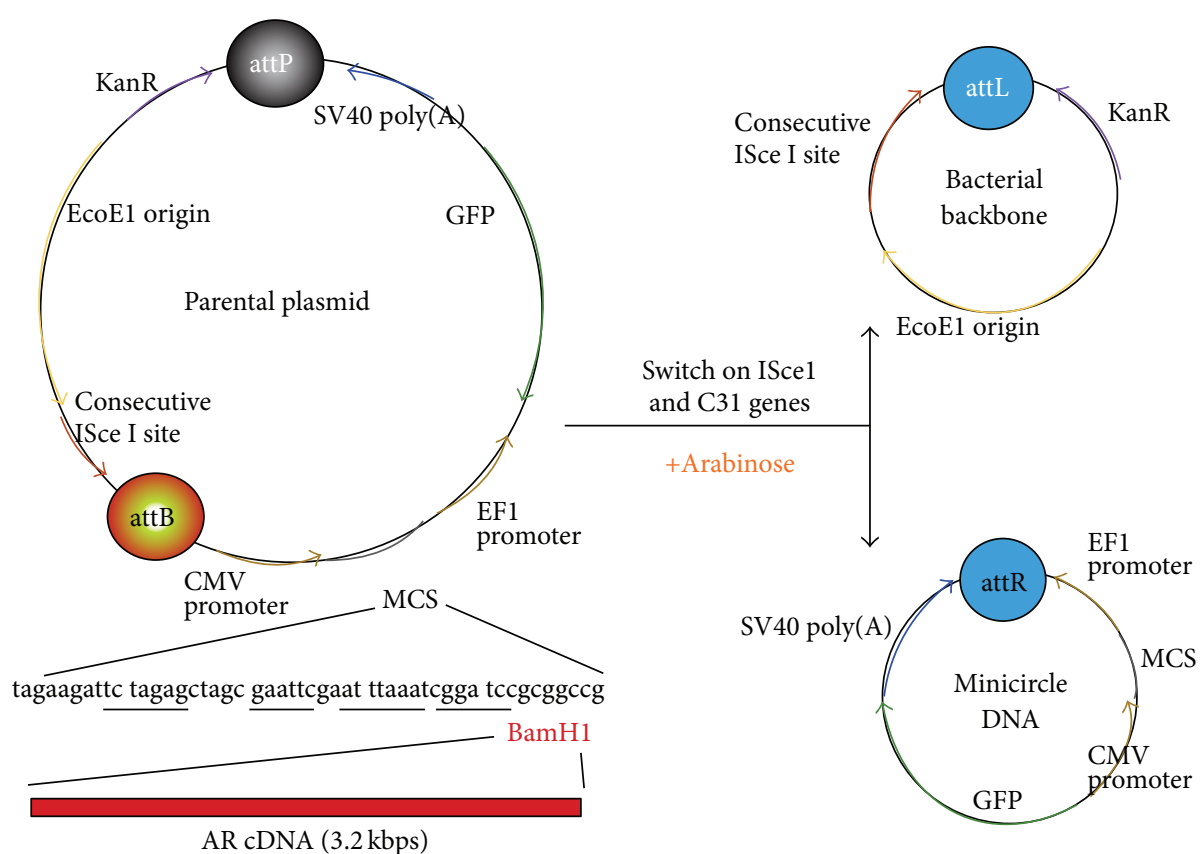

(a)

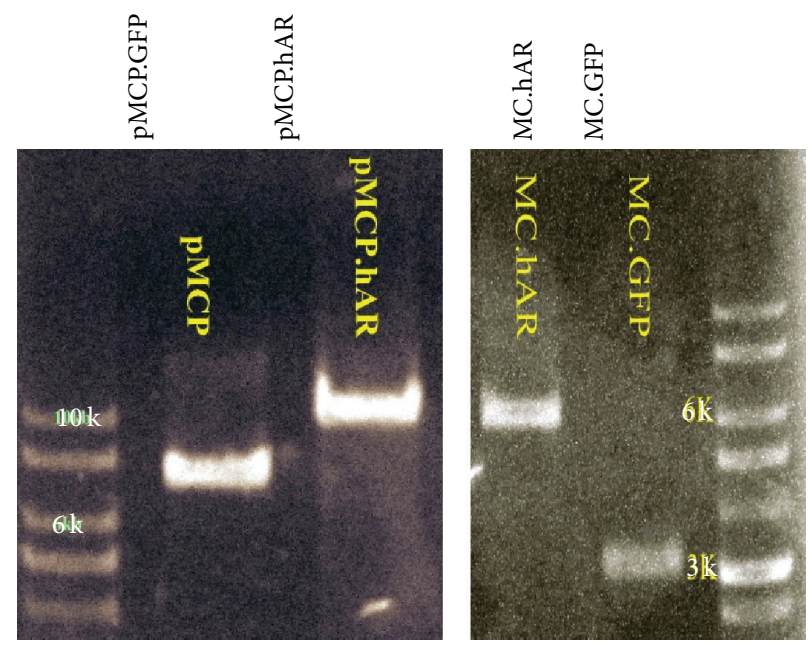

(b)

FIGURE 1: Construction of AR-expressing minicircle vectors and the production of minicircle DNA. (a) Construction of AR-expressing minicircle DNA. Parental plasmid contained antibiotics kanamycin resistance gene and replication EcoE1 Ori cassette flanked by attP and attB site recognized by $\varphi \mathrm{C} 31$ intergrase. Upon addition of arabinose, $\varphi \mathrm{C} 31$ intergrase and IScel endonuclease gene are activated by pBAD operon. The plasmid carries a CMV promoter driven GFP gene and multiple cloning sites (MCS) where AR cDNA is inserted. The $3.2 \mathrm{kbp}$ openreading frame human AR cDNA was cloned into BamH1 site on MCS to produce a $10 \mathrm{~kb}$ AR-expressing plasmid. While producing minicircle DNA, $\varphi \mathrm{C} 31$ facilitates the recombination of attP and attB sites and produces two smaller circular DNA fragments, minicircle and bacterial backbone. The backbone plasmid was linearized by IScel and further degraded by bacterial endogenous DNase, resulting in a transgene vector (minicircle) without plasmid ori and antibiotic resistance genes. (b) GFP minicircle parental plasmids with backbone (pMCP.GFP, $7 \mathrm{kbps}$; left panel, 2nd lane) and the minicircle DNA (MC.GFP, $3 \mathrm{kbps}$; right panel, 2nd lane). AR minicircle parental plasmids with backbone (pMCP.hAR, $10 \mathrm{kbps}$; left panel, 3rd lane) and the minicircle DNA (MC.hAR, $6 \mathrm{kbps}$; right panel, 1st lane). Reference molecular weight marker for parental plasmids is shown on the left-hand side of the panel. Reference molecular weight marker for minicircle DNAs is shown on the right-hand side of the panel.

At age 54 weeks, the HBV-lowDEN HCC mice were injected intravenously with $20 \mu \mathrm{g} / 100 \mu \mathrm{L} /$ mouse of LPD (MChAR or MCGFP as control group) twice weekly for 4 consecutive weeks through the caudal vein. The mice were killed two months after minicircle DNA injections. The livers were excised, stored in Tissue-Tek OCT Compound (Sakura; CA90501, USA) for frozen section, and then sliced for GFP signal detection. 


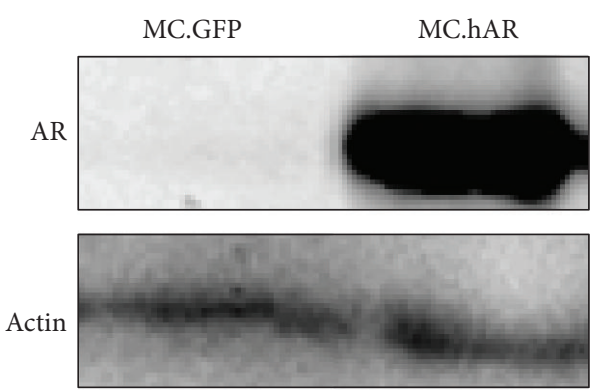

(a)

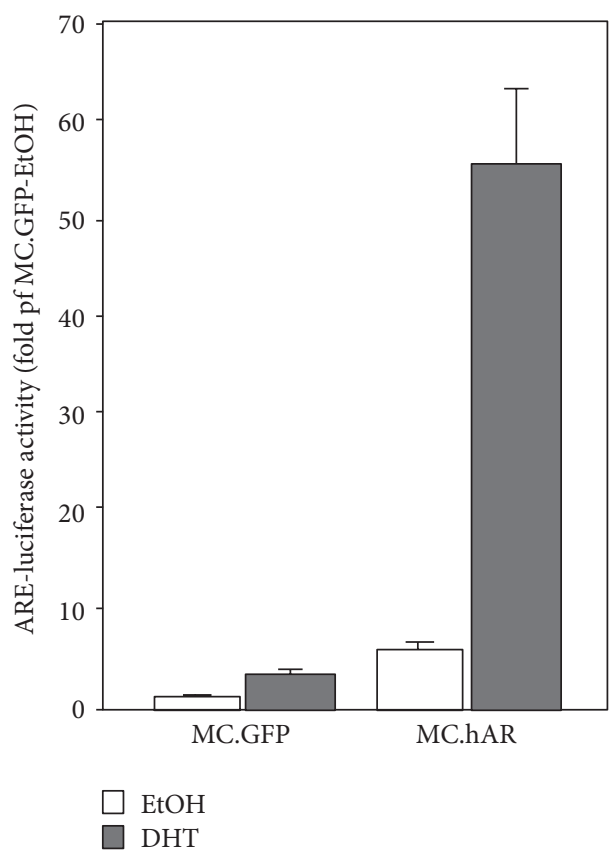

(b)

FIGURE 2: In vitro expression and functional analysis of AR minicircle DNA transfection. (a) AR protein expression in the minicircle DNA transfected 293T cells by immunoblot. The left lane is MC.GFP transfectant where the right lane is MC.hAR transfectant. Actin served as the loading control. (b) AR transactivation function was measured by ARE-luciferase assay. The MC.GFP and MC.hAR DNAs were cotransfected with ARE-luciferase into 293T cells and treated with either vehicle (ethanol; EtOH) or dihydrotestosterone (DHT, $10 \mathrm{nM}$ ) for $24 \mathrm{hrs}$. Cell lysate were harvested to analyze the dual-luciferase assay as described in Section 2. The readings of each group were normalized with those of the MC.GFP-EtOH group and plotted on a graph. The data came from at least 3 independent experiments.

2.4. In Vitro Delivery, Long-Term Culture, Immunoblot Assay, and AR Transactivation Luciferase Assay. In order to evaluate the expression latency of minicircle DNA, MC.GFP or MC.hAR was transfected into 293T cells using a calcium phosphate precipitation method [32]. Once cells grew to confluence, 1 in 10 of the cells was subcultured. GFP expression was detected using a fluorescence microscope (Nikon eclipse $80 \mathrm{i}$ ) at days $2,6,10$, and 14 . The proteins were harvested 2 days after transfection for detection of AR by western blot [27]. The plasmids pRL-TK (transfection control) and ARE-luciferase (ARE-Luc) reporter were applied in this experiment. Briefly, 1-2 $\times 10^{5}$ cells were seeded on 24 -well plates $24 \mathrm{hrs}$ before transfection. DHT $\left(10^{-8} \mathrm{M}\right)$ was added $24 \mathrm{hrs}$ after transfection. Approximately $24 \mathrm{hrs}$ later, cells were harvested and analyzed by the Dual-Luciferase Reporter Assay System (Promega) in combination with a luminometer (Promega).

2.5. Histological Examination of Minicircle-Delivered Gene Expression. Sections of normal and tumor livers were embedded in O.C.T. compound (SAKURA, USA) and frozen at $-80^{\circ} \mathrm{C}$. The tissue sections $(8 \mu \mathrm{m})$ were then obtained using a microtome (Leica freezing microtome CM1950, Germany). The sections were then fixed with $1.25 \%$ glutaraldehyde for $10 \mathrm{~min}$. All sections were inspected and images were acquired using a Nikon Eclipse 80i camera affixed to a fluorescence microscope (Nikon Microscope Eclipse 80i).

\section{Results}

3.1. AR Minicircle DNA Construction and Production. In this study, we subcloned a full-length $3.2 \mathrm{~kb}$ human AR cDNA into a minicircle parental plasmid (Figure 1(a)). We first linealized pMCP using the BamH1 endonuclease restriction enzyme and then inserted human AR cDNA to generate a $10 \mathrm{kbp}$ pMCP.hAR. To produce minicircle DNA on a larger scale, we performed a two-step incubation of plasmidtransformed ZYCY10P3S2T E. coli. The first incubation was done to replicate competent bacteria on a large scale. We then incubated $E$. coli in arabinose-containing medium at a low temperature $\left(30^{\circ} \mathrm{C}\right)$ to activate phiC31 and IScel genes so that the backbone of the plasmid would be degraded. After incubation, the minicircle DNA was extracted using a $\mathrm{CsCl}$ gradient method. The construction and verification of minicircle DNA production are shown in Figure 1(b). The parental plasmids and GFP-carrying minicircle DNA were $7 \mathrm{kbp}$ and $3 \mathrm{kbp}$ (Figure 1(b), left panel). The parental plasmid and AR-carrying miniclrcle DNA were $10 \mathrm{kbp}$ and $7 \mathrm{kbp}$ (Figure 1(b), right panel). Our analyses showed that there was little to no contamination.

In order to verify the expression and activity of $A R$ minicircle DNA, we transiently transfected MC.GFP and MC.hAR into 293T cells. The protein expression of AR was examined by immunoblot assay (Figure 2(a)). We found that AR protein was overexpressed in $293 \mathrm{~T}$ cells. We then examined AR transactivation to verify the proper folding 

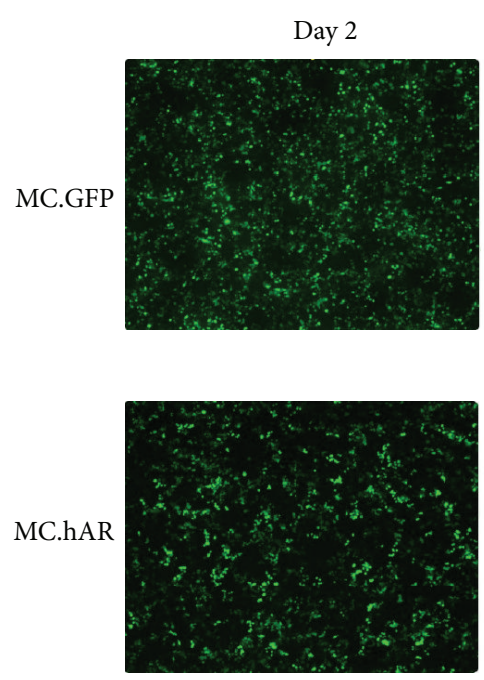

Day 6

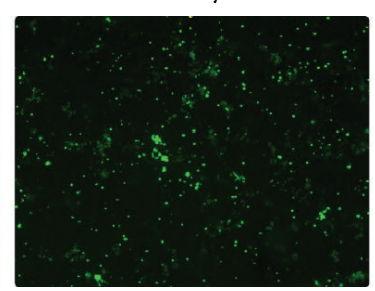

(a)

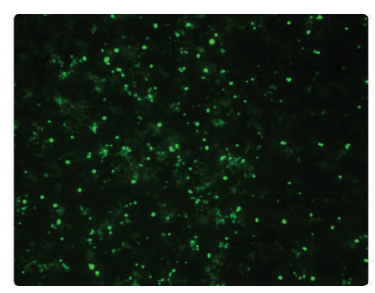

Day 10
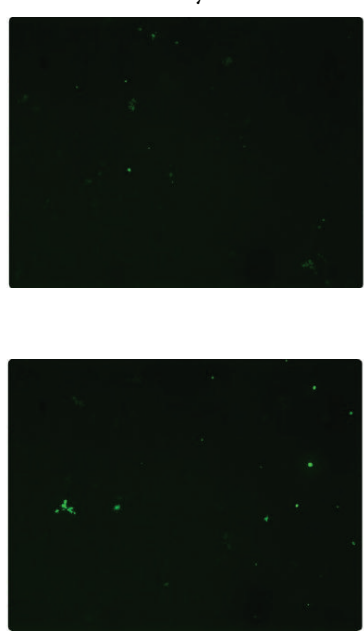

Day 14
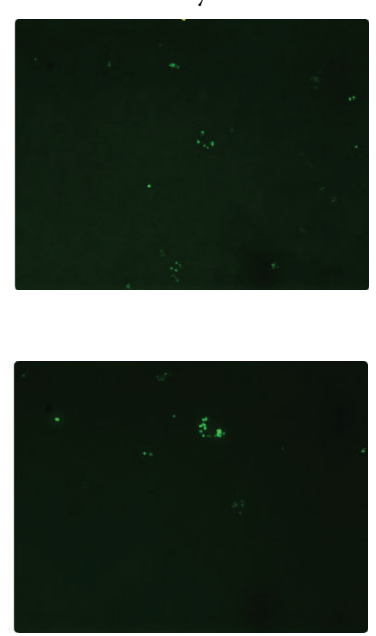

(b)

FIGURE 3: Long-term in vitro expression of minicircle DNA in 293T cells. MC.hAR or MC.GFP was transfected into 80\% confluence 293T cells, and green fluorescence was observed under fluorescence microscopy at days 2, 6, 10, and 14. The upper panels show MC.GFP transfectant and the lower panels show MC.hAR transfectant. The cells were 1/10 subcultured every three days upon cell reach to around $80 \sim 90 \%$ confluence. The strong GFP signals were still detectable on day 14 (fourth passage of subcultures).

and function of AR (Figure 2(b)). Treatment of MC.hAR transfectants with $10 \mathrm{nM}$ DHT resulted in robust induction of ARE-luciferase activity compared with ARE-luciferase activity in MC.GFP transfectants.

Taken together, we have demonstrated that our protocol results in the successful construction and production of AR minicircle DNA as well as functional expression of AR protein (Figures 1 and 2).

\subsection{Durable Expression of Minicircle DNA In Vitro and} In Vivo. After establishing our minicircle DNA expression vector, we tested whether AR protein delivered via minicircle DNA could be expressed for an extended period of time. We transfected MC.GFP and MC.hAR in HEK293T cells to measure expression duration (Figure 3 ). The initial transfection efficiency was approximately $80 \%$ (Figure 3, Left panel). We found that GFP expression was still approximately $10 \%$ after 4 passages (around 14 days; Figure 3, right panel) of both plasmids. The data suggest that MC DNA : LPD delivery exhibits excellent capacity for long-term expression.

The ideal gene delivery system is one that can efficiently and durably express genes in target organs without chromosome insertion. We, therefore, tested whether AR-carrying minicircle DNA could be expressed in normal livers and liver tumors. We found that minicircle DNA : LPD complex could deliver DNA into normal liver (Figures 4(a), 4(c), and 4(e)) and tumor liver (Figures 4(b), 4(d), and 4(f)). In addition, the GFP signal was detected in livers two months after injection.

Taken together, minicircle DNA exerts durable expression after in vitro transfection as well as in vivo delivery using Minicircle DNA : LPD complex into normal and tumor liver for 2 months.

\section{Discussion}

4.1. Failure of Viral Delivery Systems. Viral-backbone modified vectors can be used as delivery systems for DNA molecules, especially plasmids [33, 34]. For therapeutic purposes, the transgene of interest is assembled in the viral genome, where the virus uses its innate mechanism of infection to enter the cells and release the expression cassette. The gene then enters the nucleus and sometimes integrates into the host genome (i.e., lentiviral vector) and is eventually expressed. Gene expression using viral vectors has been achieved with high transfection efficiencies in organs such as kidney [35], muscle [36], ovary [37], and liver [38, 39]. However, there are several concerns regarding the use of viruses as delivery vectors. The chief concern is the toxicity of the viruses and the potential for generating a strong immune response owing to their capsids. Such toxicities have been observed in numerous animal models [40, 41]. For example, traces of adenovirus titers were detected in seminal fluids of a male patient who had earlier received adenoviral based gene therapy, further compounding the fear of possible germline tampering [42]. Adenoviral vectors used for gene therapy for cystic fibrosis were shown to cause a strong immunogenic response [43]. The death of a patient with respiratory and multiple organ failure participating in a FDA-approved gene therapy clinical trial in 1999 was attributed to lethal immune response to the adenovirus vector used to deliver the gene. This case led to temporary suspension of all gene therapy trials in the United States [44]. Although clinical trials have resumed, this event as well as a few others (Clinical trial ID number: NCT00844623) and (http://clinicaltrials.gov/ct2/results?term=adenoviral \pm vector $\% 2 \mathrm{C} \pm$ liver\&Search=Search) has raised tremendous concern over the safety of using viruses for gene therapy. 


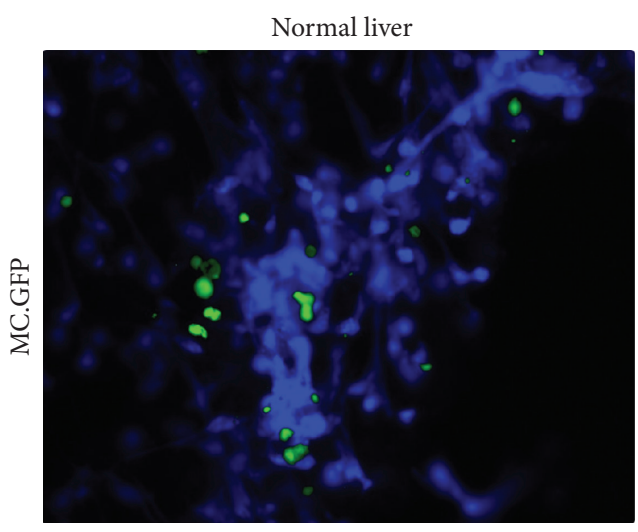

(a)

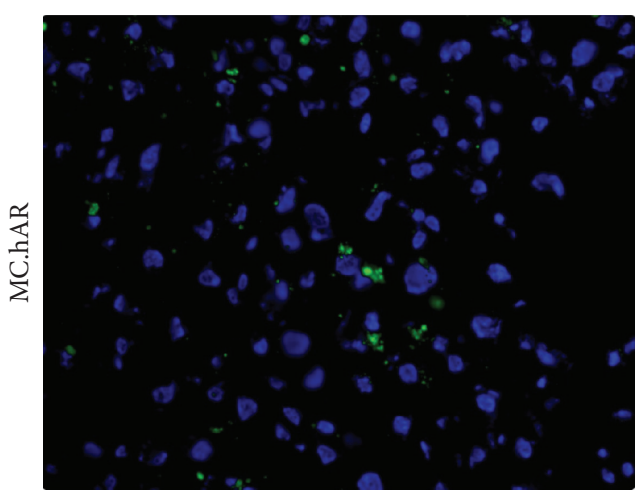

(c)

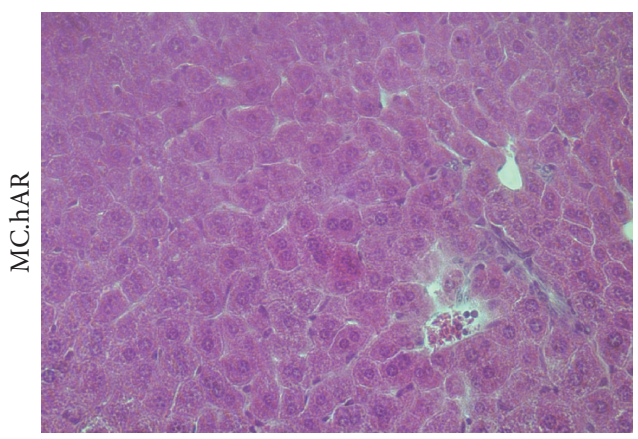

(e)

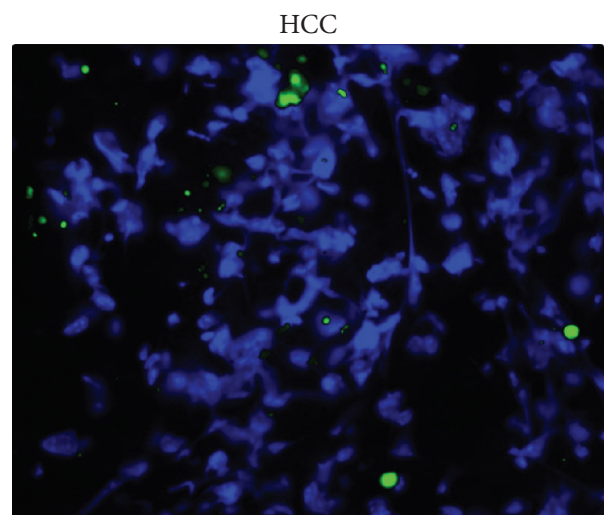

(b)

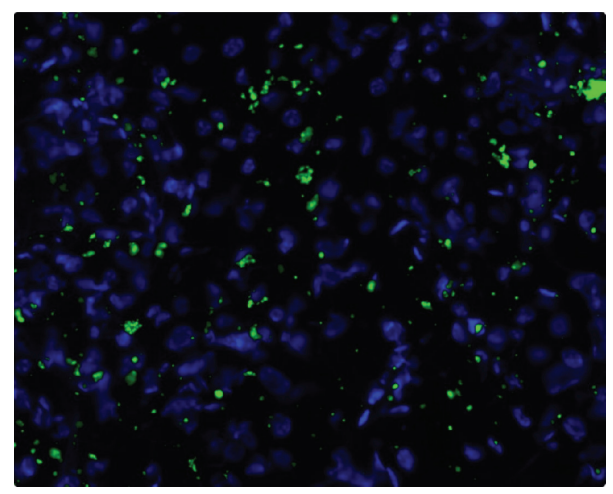

(d)

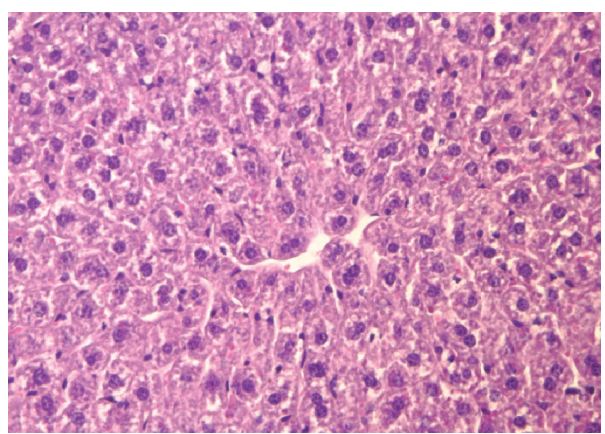

(f)

FIGURE 4: Long-term in vivo expression of minicircle DNA in normal and HBV-induced tumor livers. (a) GFP signal of MC.GFP injected normal mouse liver under fluorescence microscope. (b) GFP signals of MC.GFP injected tumor mouse liver under fluorescence microscope. (c) GFP signals of MC.hAR injected normal mouse liver under fluorescence microscope. (d) GFP signals of MC.hAR injected tumor mouse liver under fluorescence microscope. (e) H\&E staining image of nontumor counterpart of HBV-HCC mouse after MC.hAR: LPD delivery. (f) H\&E staining image of tumor lesion of HBV-HCC mouse after MC.hAR : LPD delivery.

In addition, the integration of therapeutic genes into the host genome by a virus takes place in a random fashion. There is no control over the exact location of the insertion of a gene. Random gene insertion can cause insertion mutagenesis that may inhibit expression of normal cellular genes or activate oncogenes, with deleterious consequences [45]. Both these two concerns are not occur while using minicircle DNA : LPD technology for nonviral mediated gene transduction nature, and not chromosome-insertion-sequence contain in minicircle DNA.
4.2. Advantages of the Minicircle-LPD Delivery System and Its Potential for Future Cancer Therapy. In contrast to viral delivery systems, lipid nanoparticles are generally less immunogenic owing to the surface PEGylation [46]. However, toxicity related to liposomal gene transfer has been observed. Acute inflammation reactions have been observed in animals treated with airway instillation and intravenous injection of lipoplex [47]. Symptoms include induction of inflammatory cytokines, neutrophil infiltration in lungs, decrease in white cell counts, and in some cases tissue injury 
in liver and spleen [48]. Part of the inflammatory response seen in treated lungs is related to the unmethylated $\mathrm{CpG}$ sequences found in plasmids of bacterial origin. A potent immune stimulant, unmethylated $\mathrm{CpG}$ sequences, triggers release of proinflammatory cytokines [14]. Cationic lipids in lipoplexes are capable of enhancing the unmethylated $\mathrm{CpG}$ effect [49]. Minicircle DNA, which is devoid of bacterial unmethylated $\mathrm{CpG}$ sequences, reduces immune response caused by unmethylated $\mathrm{CpG}$, enhances expression level, and prolongs expression duration [16]. Further, minicircle DNA was condensed by protamine, was wrapped as a core by lipids, and therefore reduced the opportunity of exposing to immune cells to cause immune response. Another advantage of using the LPD delivery system is that LPD tends to accumulate in tumors because of the EPR effect, thus greatly enhancing selectivity [1].

\section{Conclusion}

To the best of our knowledge, this is the first study to use minicircle DNA-LPD to deliver a metastasis suppressor gene in normal and spontaneous-tumor livers. In this study, we used LPD containing minicircle DNA to deliver a $100 \mathrm{kD}$ protein to normal and tumor livers in mice. Our results show that AR protein was robustly expressed for at least two months. The applications of this success would be in the following aspects:

(1) cancer therapies usually require a long lasting concentration or expression in the target organ in order to have therapeutic effects. Our model would serve this purpose;

(2) one disadvantage of viral-mediated gene therapy would be the systemic immune response caused by viral particle. The LPD carrying minicircle DNA has minimal immune problem which allows for multiple interventions.

$\begin{array}{ll}\text { Abbreviations } \\ \text { EPR: } & \text { Enhanced permeability and retention } \\ \text { HCC: } & \text { Hepatocellular carcinoma } \\ \text { kbps: } & \text { Kilo-base pairs } \\ \text { HBV: } & \text { Hepatitis B Virus } \\ \text { DOTAP: } & \text { N-[1-(2,3-Dioleoyloxy)propyl]-N,N,N- } \\ & \text { trimethyl-ammoniummethyl-sulfate } \\ \text { AR: } & \text { Androgen receptor } \\ \text { GFP: } & \text { Green fluorescence protein } \\ \text { cDNA: } & \text { Complementary DNA } \\ \text { kD: } & \text { Kilodalton } \\ \text { MC: } & \text { Minicircles } \\ \text { FIX: } & \text { Factor IX } \\ \text { AAT: } & \text { Alphal-antitrypsin } \\ \text { DEN: } & \text { Diethylnitrosamine } \\ \text { ARE: } & \text { Androgen response element. }\end{array}$

\section{Conflict of Interests}

All the authors claimed no conflict of interests in this work.

\section{Authors' Contribution}

Tian-You Chang and Chin-Ying Chung executed on majority of the experiments and draft the paper. Wei-Min Chuang is responsible for animal breeding, housing, and injections. Long-Yuan Li and Long-Bin Jeng contributed on scientific opinions and paper editing. Wen-Lung Ma designed, composed the paper, and supported the entire project. Tian-You Chang and Chin-Ying Chung contributed equally on this work.

\section{Acknowledgments}

The authors deeply appreciated Professor James Ou in University of Southern California for providing HBV-transgene mouse. This work was supported by Taiwan National Science Council Grants NSC101-2314-B-039-027-MY3 and National Health Research Institution Grants NHRI-EX102-10214BC to Wen-Lung Ma and NSC102-2321-B-039-002, NSC102-2325B-039-002, NSC99-2632-B-039-001-MY3, and MOHW102TD-PB-111-NSC105 to Long-Yuan Li. Tian-You Chang and Chin-Ying Chung contributed equally in this work.

\section{References}

[1] H. Maeda, J. Wu, T. Sawa, Y. Matsumura, and K. Hori, “Tumor vascular permeability and the EPR effect in macromolecular therapeutics: a review," Journal of Controlled Release, vol. 65, no. 1-2, pp. 271-284, 2000.

[2] H. Maeda, "SMANCS and polymer-conjugated macromolecular drugs: advantages in cancer chemotherapy," Advanced Drug Delivery Reviews, vol. 46, no. 1-3, pp. 169-185, 2001.

[3] P. A. Vasey, S. B. Kaye, R. Morrison et al., "Phase I clinical and pharmacokinetic study of PK1 [N-(2- hydroxypropyl)methacrylamide copolymer doxorubicin]: first member of a new class of chemotherapeutic agents-drug-polymer conjugates," Clinical Cancer Research, vol. 5, no. 1, pp. 83-94, 1999.

[4] F. Liu, Y. K. Song, and D. Liu, "Hydrodynamics-based transfection in animals by systemic administration of plasmid DNA," Gene Therapy, vol. 6, no. 7, pp. 1258-1266, 1999.

[5] X. Gao, K.-S. Kim, and D. Liu, "Nonviral gene delivery: what we know and what is next," AAPS Journal, vol. 9, no. 1, article 9, pp. E92-E104, 2007.

[6] C. H. Miao, A. R. Thompson, K. Loeb, and X. Ye, "Long-term and therapeutic-level hepatic gene expression of human factor IX after naked plasmid transfer in vivo," Molecular Therapy, vol. 3, no. 6, pp. 947-957, 2001.

[7] C. H. Miao, X. Ye, and A. R. Thompson, "High-level factor VIII gene expression in vivo achieved by nonviral liver-specific gene therapy vectors," Human Gene Therapy, vol. 14, no. 14, pp. 12971305, 2003.

[8] J. Jiang, E. Yamato, and J.-I. Miyazaki, "Intravenous delivery of naked plasmid DNA for in vivo cytokine expression," Biochemical and Biophysical Research Communications, vol. 289, no. 5, pp. 1088-1092, 2001.

[9] J. Yang, S. Chen, L. Huang, G. K. Michalopoulos, and Y. Liu, "Sustained expression of naked plasmid DNA encoding hepatocyte growth factor in mice promotes liver and overall body growth," Hepatology, vol. 33, no. 4, pp. 848-859, 2001. 
[10] S. F. Aliño, A. Crespo, and F. Dasí, "Long-term therapeutic levels of human alpha-1 antitrypsin in plasma after hydrodynamic injection of nonviral DNA," Gene Therapy, vol. 10, no. 19, pp. 1672-1679, 2003.

[11] J. R. Ortaldo, R. T. Winkler-Pickett, E. W. Bere Jr., M. Watanabe, W. J. Murphy, and R. H. Wiltrout, "In vivo hydrodynamic delivery of cDNA encoding IL-2: rapid, sustained redistribution, activation of mouse NK cells, and therapeutic potential in the absence of NKT cells," Journal of Immunology, vol. 175, no. 2, pp. 693-699, 2005.

[12] T. Suda and D. Liu, "Hydrodynamic gene delivery: its principles and applications," Molecular Therapy, vol. 15, no. 12, pp. 20632069, 2007.

[13] A. M. Krieg, "Direct immunologic activities of CpG DNA and implications for gene therapy," Journal of Gene Medicine, vol. 1, no. 1, pp. 56-63, 1999.

[14] G. McLachlan, B. J. Stevenson, D. J. Davidson, and D. J. Porteous, "Bacterial DNA is implicated in the inflammatory response to delivery of DNA/DOTAP to mouse lungs," Gene Therapy, vol. 7, no. 5, pp. 384-392, 2000.

[15] Z.-Y. Chen, C.-Y. He, A. Ehrhardt, and M. A. Kay, "Minicircle DNA vectors devoid of bacterial DNA result in persistent and high-level transgene expression in vivo," Molecular Therapy, vol. 8, no. 3, pp. 495-500, 2003.

[16] N. S. Yew, H. Zhao, M. Przybylska et al., "CpG-depleted plasmid DNA vectors with enhanced safety and long-term gene expression in vivo," Molecular Therapy, vol. 5, no. 6, pp. 731-738, 2002.

[17] P. L. Felgner, T. R. Gadek, M. Holm et al., "Lipofection: a highly efficient, lipid-mediated DNA-transfection procedure," Proceedings of the National Academy of Sciences of the United States of America, vol. 84, no. 21, pp. 7413-7417, 1987.

[18] D. Liu, T. Ren, and X. Gao, "Cationic transfection lipids," Current Medicinal Chemistry, vol. 10, no. 14, pp. 1307-1315, 2003.

[19] T. Merdan, J. Kopeček, and T. Kissel, "Prospects for cationic polymers in gene and oligonucleotide therapy against cancer," Advanced Drug Delivery Reviews, vol. 54, no. 5, pp. 715-758, 2002.

[20] X. Gao and L. Huang, "Potentiation of cationic liposomemediated gene delivery by polycations," Biochemistry, vol. 35, no. 3, pp. 1027-1036, 1996.

[21] S.-D. Li, S. Chono, and L. Huang, "Efficient gene silencing in metastatic tumor by siRNA formulated in surface-modified nanoparticles," Journal of Controlled Release, vol. 126, no. 1, pp. 77-84, 2008.

[22] S.-D. Li, Y.-C. Chen, M. J. Hackett, and L. Huang, "Tumortargeted delivery of siRNA by self-assembled nanoparticles," Molecular Therapy, vol. 16, no. 1, pp. 163-169, 2008.

[23] S.-D. Li and L. Huang, "Nanoparticles evading the reticuloendothelial system: role of the supported bilayer," Biochimica et Biophysica Acta, vol. 1788, no. 10, pp. 2259-2266, 2009.

[24] C. Chang, J. Kokontis, and S. Liao, "Molecular cloning of human and rat complementary DNA encoding androgen receptors," Science, vol. 240, no. 4850, pp. 324-326, 1988.

[25] C.-L. Ma, C.-L. Hsu, M.-H. Wu et al., "Androgen receptor is a new potential therapeutic target for the treatment of hepatocellular carcinoma," Gastroenterology, vol. 135, no. 3, pp. 947-955, 2008.

[26] M.-H. Wu, W.-L. Ma, C.-L. Hsu et al., "Androgen receptor promotes hepatitis B virus-induced hepatocarcinogenesis through modulation of hepatitis B virus RNA transcription," Science Translational Medicine, vol. 2, no. 32, article 32ra35, 2010.
[27] W. L. Ma, C. L. Hsu, C. C. Yeh et al., "Hepatic androgen receptor suppresses hepatocellular carcinoma metastasis through modulation of cell migration and anoikis," Hepatology, vol. 56, pp. 176-185, 2012.

[28] Y. Zheng, W.-L. Chen, S. G. Louie, T. S. B. Yen, and J.-H. J. Ou, "Hepatitis B virus promotes hepatocarcinogenesis in transgenic mice," Hepatology, vol. 45, no. 1, pp. 16-21, 2007.

[29] M. A. Kay, C.-Y. He, and Z.-Y. Chen, "A robust system for production of minicircle DNA vectors," Nature Biotechnology, vol. 28, no. 12, pp. 1287-1289, 2010.

[30] Y. Zheng, J. Li, and J.-H. Ou, "Regulation of hepatitis B virus core promoter by transcription factors HNF1 and HNF4 and the viral X protein," Journal of Virology, vol. 78, no. 13, pp. 69086914, 2004.

[31] J. Li, Z. Xu, Y. Zheng, D. L. Johnson, and J.-H. Ou, “Regulation of hepatocyte nuclear factor 1 activity by wild-type and mutant hepatitis B virus X proteins," Journal of Virology, vol. 76, no. 12, pp. 5875-5881, 2002.

[32] R. E. Kingston, C. A. Chen, and J. K. Rose, "Calcium phosphate transfection," in Current Protocols in Molecular Biology, F. M. Ausubel, Ed., chapter 9, unit 9 1, 2003.

[33] C. Mah, B. J. Byrne, and T. R. Flotte, "Virus-based gene delivery systems," Clinical Pharmacokinetics, vol. 41, no. 12, pp. 901-911, 2002.

[34] M. T. Lotze and T. A. Kost, "Viruses as gene delivery vectors: application to gene function, target validation, and assay development," Cancer Gene Therapy, vol. 9, no. 8, pp. 692-699, 2002.

[35] Y.-H. H. Lien and L.-W. Lai, "Gene therapy for renal disorders: what are the benefits for the elderly?" Drugs and Aging, vol. 19, no. 8, pp. 553-560, 2002.

[36] D. J. Wells, A. Ferrer, and K. E. Wells, "Immunological hurdles in the path to gene therapy for Duchenne muscular dystrophy," Expert Reviews in Molecular Medicine, vol. 4, pp. 1-23, 2002.

[37] J. K. Wolf and A. D. Jenkins, "Gene therapy for ovarian cancer (review)," International Journal of Oncology, vol. 21, no. 3, pp. 461-468, 2002.

[38] B. Sangro, G. Mazzolini, M. Ruiz et al., "A phase i clinical trial of thymidine kinase-based gene therapy in advanced hepatocellular carcinoma," Cancer Gene Therapy, vol. 17, no. 12, pp. 837-843, 2010.

[39] G. Tian, J. Liu, J. S. R. Zhou, and W. Chen, "Multiple hepatic arterial injections of recombinant adenovirus p53 and 5fluorouracil after transcatheter arterial chemoembolization for unresectable hepatocellular carcinoma: a pilot phase II trial," Anti-Cancer Drugs, vol. 20, no. 5, pp. 389-395, 2009.

[40] M. A. Kay, J. C. Glorioso, and L. Naldini, "Viral vectors for gene therapy: the art of turning infectious agents into vehicles of therapeutics," Nature Medicine, vol. 7, no. 1, pp. 33-40, 2001.

[41] T. L. Timme, S. J. Hall, R. Barrios, S. L. C. Woo, E. AguilarCordova, and T. C. Thompson, "Local inflammatory response and vector spread after direct intraprostatic injection of a recombinant adenovirus containing the herpes simplex virus thymidine kinase gene and ganciclovir therapy in mice," Cancer Gene Therapy, vol. 5, no. 2, pp. 74-82, 1998.

[42] L. Tenenbaum, E. Lehtonen, and P. E. Monahan, "Evaluation of risks related to the use of adeno-associated virus-based vectors," Current Gene Therapy, vol. 3, no. 6, pp. 545-565, 2003.

[43] T. R. Flotte and B. L. Laube, "Gene therapy in cystic fibrosis," Chest, vol. 120, no. 3, pp. 124S-131S, 2001.

[44] S. E. Raper, N. Chirmule, F. S. Lee et al., "Fatal systemic inflammatory response syndrome in a ornithine transcarbamylase 
deficient patient following adenoviral gene transfer," Molecular Genetics and Metabolism, vol. 80, no. 1-2, pp. 148-158, 2003.

[45] S. D. Patil, D. G. Rhodes, and D. J. Burgess, "DNA-based therapeutics and DNA delivery systems: a comprehensive review," The AAPS Journal, vol. 7, no. 1, article 9, pp. E61-E77, 2005.

[46] A. Vonarbourg, C. Passirani, P. Saulnier, P. Simard, J. C. Leroux, and J. P. Benoit, "Evaluation of pegylated lipid nanocapsules versus complement system activation and macrophage uptake," Journal of Biomedical Materials Research A, vol. 78, no. 3, pp. 620-628, 2006.

[47] Y. K. Song, "Characterization of cationic liposome-mediated gene transfer in vivo by intravenous administration," Human Gene Therapy, vol. 8, no. 13, pp. 1585-1594, 1997.

[48] N. S. Yew and R. K. Scheule, "Toxicity of cationic lipid-DNA complexes," Advances in Genetics, vol. 53, pp. 189-214, 2005.

[49] N. S. Yew, K. X. Wang, M. Przybylska et al., "Contribution of plasmid DNA to inflammation in the lung after administration of cationic lipid:pDNA complexes," Human Gene Therapy, vol. 10, no. 2, pp. 223-234, 1999. 


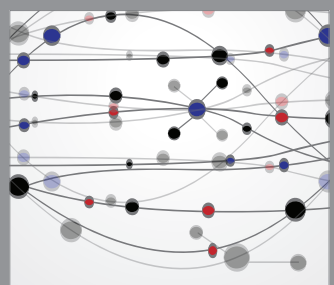

The Scientific World Journal
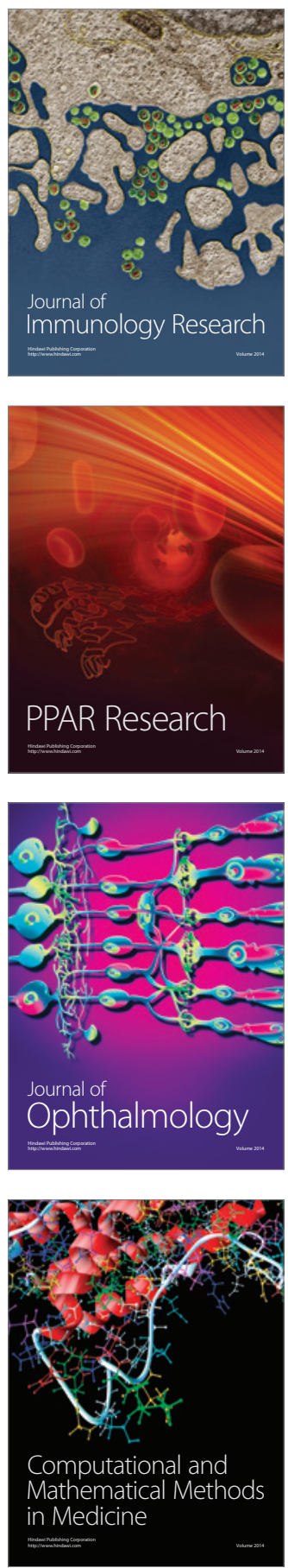

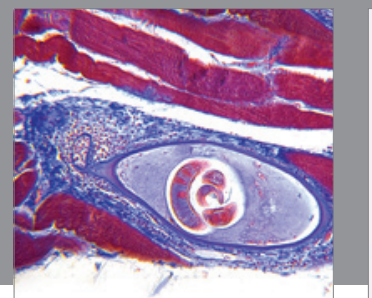

Gastroenterology

Research and Practice
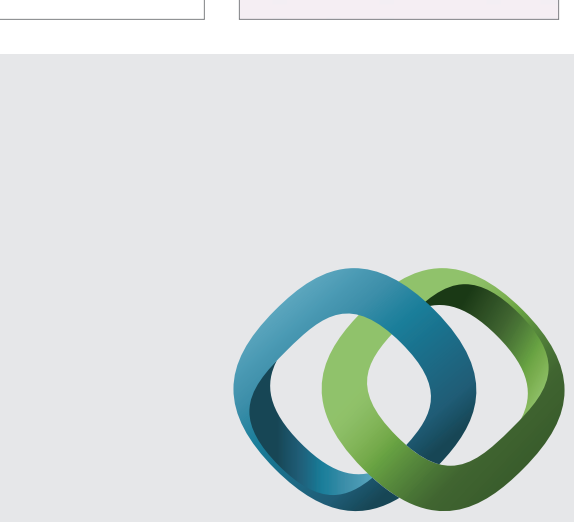

\section{Hindawi}

Submit your manuscripts at

http://www.hindawi.com
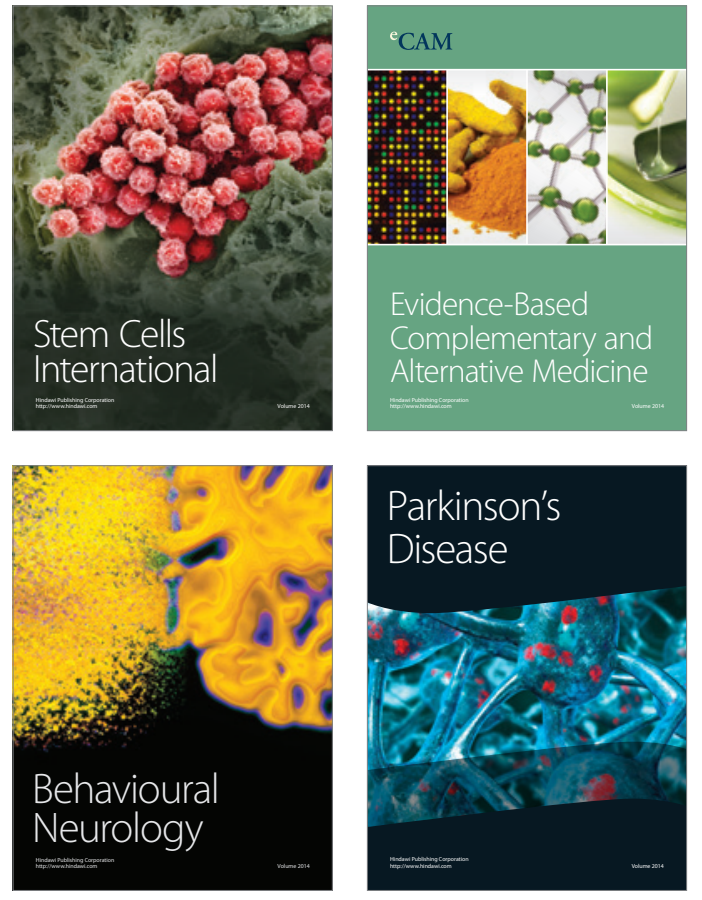
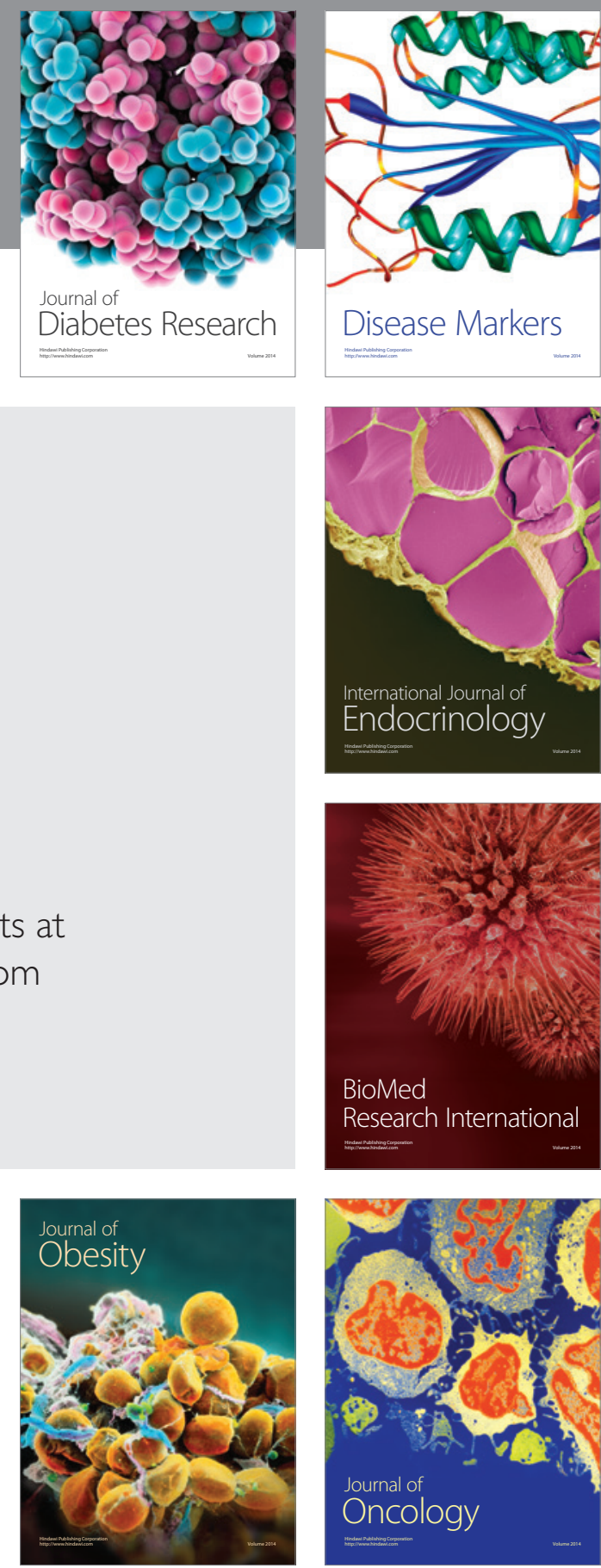

Disease Markers
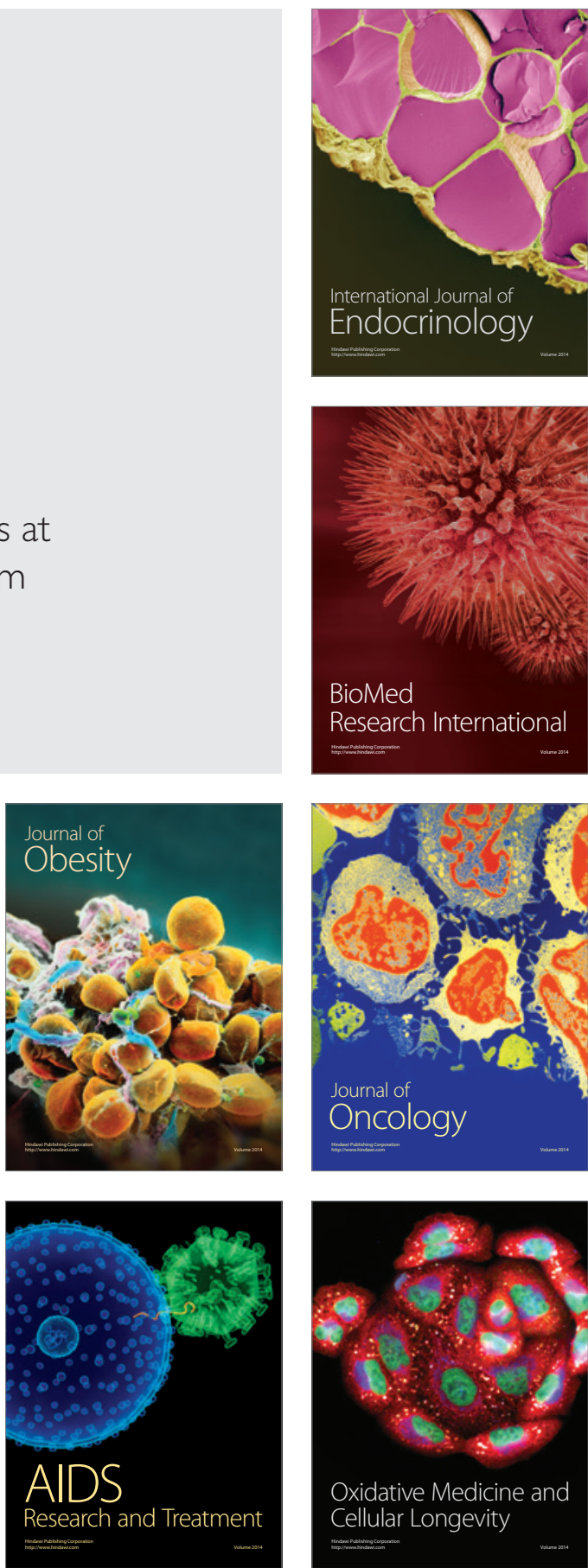